\title{
PREVALENCE OF VARIOUS TYPES OF STRABISMUS AMONG PATIENTS ATTENDING A TERTIARY EYE CARE HOSPITAL AT TIRUCHIRAPPALLI
}

\author{
Ramesh Rajasekaran'1, R. Meena Kumari², Ashok Balagopal3, Prasanna Venkatesh Ramesh', Kalai Mohan ${ }^{5}$
}

${ }^{1}$ Chairman, Mahathma Eye Hospital, Tiruchirappalli, Tamilnadu, India.

${ }^{2}$ Medical Director, Department of Ophthalmology, Mahathma Eye Hospital, Tiruchirappalli, Tamilnadu, India.

${ }^{3}$ General Ophthalmologist, Department of Ophthalmology, Mahathma Eye Hospital, Tiruchirappalli, Tamilnadu, India.

${ }^{4}$ Fellow-Medical Officer, Dr. Sathyan Hospital, Coimbatore, Tamilnadu, India.

${ }^{5}$ General Ophthalmologist, Department of Ophthalmology, Mahathma Eye Hospital, Tiruchirappalli, Tamilnadu, India.

\section{BACKGROUND}

ABSTRACT

Strabismus is a clinical condition in which the eyes are not aligned properly and are pointed in different directions when looking at an object. The aim of this study is to find out the occurrence of strabismus in a limited population visiting a tertiary level eye care centre.

Aims and Objectives-

1. To determine the prevalence of different types of strabismus in patients of all age groups visiting a tertiary eye care hospital at Tiruchirapalli.

2. To create awareness among the patients about the effects of strabismus and also the treatment options for the correction of strabismus.

\section{MATERIALS \& METHODS}

A hospital-based observational study was conducted using data from archives of a tertiary level eye care hospital at Tiruchirapalli from 2014 to 2018. The study consisted of using records of patients having strabismus. From these, the types of strabismus and syndrome associated to it in some cases were recorded.

\section{RESULTS}

2,217 patients were found to have strabismus during the period 2014 to 2018 . Exotropia was found to be the most common type of strabismus in this population followed by esotropia, paralytic strabismus and intermittent exotropia being the least common.

\section{CONCLUSION}

Extropia was found to be the most common type of strabismus in this population followed by esotropia, paralytic and intermittent type being the least common. These data support the assumption that screening strabismus in developing countries could be useful in early detection, appropriate management and prevention of strabismus.

\section{KEY WORDS}

Strabismus, Exotropia, Esotropia, Intermittent Type, Paralytic Squint, Brown Syndrome, Duane Refraction Syndrome.

HOW TO CITE THIS ARTICLE: Rajasekaran R, Kumari RM, Balagopal A, et al. Prevalence of various types of strabismus among patients attending a tertiary eye care hospital at Tiruchirappalli. J. Evolution Med. Dent. Sci. 2018;7(52):5484-5487, DOI: $10.14260 /$ jemds/2018/1213

\section{BACKGROUND}

Strabismus, most commonly known as squint or crossed eye or walled eye is a vision condition where a person cannot align both eyes simultaneously under normal condition. ${ }^{1}$ One or both the eye may turn up or down, in or out and an eye turn may be all the time (Constant) or only sometimes (Intermittent). It is usually accompanied by abnormal ocular mobility, double vision, poor vision or abnormal head positioning. ${ }^{2} \& 3$ Strabismus is caused by muscle dysfunction, far sightedness, problems in the brain, trauma and infections.

A neglected case of strabismus may lead to a condition of loss of binocular single vision.

'Financial or Other Competing Interest': None.

Submission 13-11-2018, Peer Review 06-12-2018,

Acceptance 13-12-2018, Published 24-12-2018.

Corresponding Author:

Dr. Ramesh Rajasekaran,

Chairman, Mahathma Eye Hospital,

Tiruchirappalli, Tamilnadu, India.

E-mail:vigal6@gmail.com

DOI: $10.14260 /$ jemds $/ 2018 / 1213$

In adulthood, presence of strabismus may lead to psychological problems such as poor self-esteem, depression, poor interpersonal relationship and poor job opportunities because of cosmetically undesirable appearance. 4 So the patients with strabismus are suggested to have their eyes aligned optically or surgically to maximize their binocular vision outcome. ${ }^{5}$ Strabismus does not get cured on its own. Therefore, treatment should be initiated as soon as it is diagnosed or at least as early as possible. Early diagnosis and treatment help us achieve the best binocular vision possible and also diminishes psychological problems. ${ }^{6}$

This study presents the relative presence of strabismus among a limited population visiting a tertiary eye care hospital from the year 2014 to 2018. This information may be used for planning appropriate awareness program regarding the treatment for strabismus and reduce their burden.

\section{MATERIALS AND METHODS}

Study Design

The study was done in Mahatma Eye Hospital, a tertiary eye care hospital located in Trichy, Tamil Nadu. This was a cross- 
sectional study where 2217 patients were diagnosed to have strabismus.

Inclusion Criteria- Age from 2 years to 56-year-old.

Exclusion Criteria- Age younger than 2 year and above 56 years old.

\section{Screening Procedure}

Estimation of the deviation of eye was done using Hirschberg's test. Refraction, visual acuity, presence of syndrome and full orthoptic analysis for the suspects were carried out. Every patient was categorized into one of the six groups: esotropia, exotropia, intermittent type, paralytic strabismus, Brown syndrome and Duane Refraction Syndrome (DRS).

\section{Data Analysis}

Examination forms were cross-checked for completeness of data. All data were entered and analysed using SPSS (Statistical Package for Social Sciences) computer program. The prevalence of exotropia, esotropia, intermittent, paralytic strabismus, Brown syndrome and Duane Refraction Syndrome (DRS) were calculated in percentage and presented in tables and figures as descriptive statistics.

\section{RESULTS}

Strabismus is a disorder in which the eyes don't look the object exactly in the same direction at the same time. The present study was aimed to find out the occurrence of strabismus in a limited population visiting at Mahatma Eye Hospital, a tertiary eye care hospital located in Trichy, Tamil Nadu, S. India. This was a cross-sectional study where 2217 patients were diagnosed with strabismus.

A maximum of 581 patients were detected as squint in the year 2016, followed by 2014, in which 403 patients were identified as squint. The prevalence of strabismus in 2016 and 2014 is $7.4 / 1000$ and 5.2/1000 patients respectively. In 2018, 457 patients were diagnosed as squint and the prevalence of strabismus among the patients was predicted as 7.8/1000 patients (Figure - 1) till the month of September. This reveals that the patients reported with disease was maximum in the year 2016 (581 patients) when compared to the year 2015 (345). The results were tabulated in the table -1 .

Age distribution of patients with strabismus between 2014 to 2018 was analysed and the data were presented in the figure -2 . In the year $2014,50 \%$ of them were adults and $50 \%$ were children. In $2015,41 \%$ of patients were adults and $59 \%$ of them were children. In $2016,30 \%$ cases were adults and $70 \%$ cases were children. In $2017,37 \%$ of the patients were adults and $63 \%$ of were children. In $2018,38 \%$ cases were adults and 62 were children. This study revealed that, more children were reported than adult in recent years when compared to previous years. This is due to increased awareness among the parents regarding safe surgical treatment modalities available to restore their vision and also cosmetic appearance.
The distribution of the different types of strabismus with frequency and percentage from the year 2014 to September 2018 is displayed in table-2. Among these, the frequency of exotropia, esotropia and intermittent were comparatively high in the year 2016 in which 291, 207 and 35 patients were recorded respectively. It was comparatively very low in 2015 , in which 192, 103 and 7 patients were observed. The paralytic strabismus was found to be maximum in the year 2018. Only minimal variation was found in the number of patients with paralytic squint. Among the different types of strabismus, the most prevalent type of strabismus is exotropia which was found in about 1246 patients (57.53\%), esotropia come second which includes 697 cases $(32.18 \%)$ followed by paralytic type which is present in 122 cases (5.63\%) and intermittent type in 101 cases (4.6\%) respectively from the year 2014 to September 2018 (Figure 3).

The prevalence of syndrome associated strabismus was analysed. In the year 2014, 10 cases (90.9\%) had DRS and only 1 case $(9.09 \%)$ had Brown syndrome. In 2015, 11 cases (73.3\%) reported with DRS and 4 cases (26.6\%) with Brown syndrome. In 2015 and 2016, DRS was seen in 17 cases $(89.4 \%)$ and 4 cases $(80 \%)$ and Brown syndrome was present in 2 cases $(10.5 \%)$ and 1 case $(20 \%)$ respectively. In the year 2018, data was collected upto month of September which showed 8 cases $(72.7 \%)$ of DRS and 3 cases (27.2\%) of Brown syndrome. These results were tabulated in table 3 . From the data collected from the year 2014 to September 2018, Duane refractory syndrome is found to be more prevalent than Brown syndrome. Duane Refractory Syndrome was seen in 50 cases (81.97\%) and Brown syndrome in 11 i.e $18.03 \%$ cases only (Figure - 4).

\begin{tabular}{|c|c|c|}
\hline Year & Squint & Prevalence Per 1000 OPD \\
\hline 2014 & 403 & 5.2 \\
\hline 2015 & 345 & 4.8 \\
\hline 2016 & 581 & 7.4 \\
\hline 2017 & 431 & 5.8 \\
\hline 2018 & 457 & 7.8 \\
\hline \multicolumn{3}{|c|}{ Table 1. Year-Wise Prevalence of Squint among the Study } \\
Population (2014-2018) \\
\hline
\end{tabular}

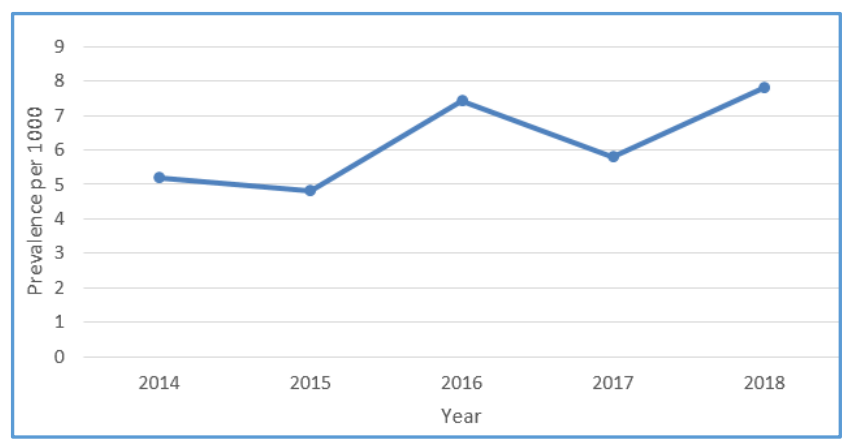

Figure 1. Time Trends in Prevalence of Squint among Study Population (2014-2018) 


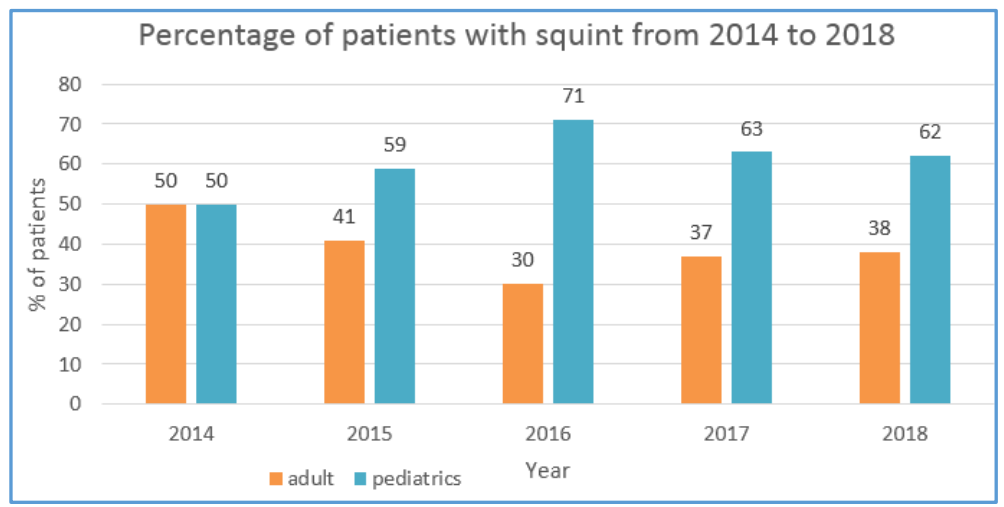

Figure 2. Age Distribution of Patients with Strabismus from 2014 to 2018

\begin{tabular}{|c|c|c|c|c|c|c|c|c|c|c|}
\hline \multirow{3}{*}{$\begin{array}{c}\text { Type of } \\
\text { Strabismus }\end{array}$} & \multicolumn{10}{|c|}{ Year } \\
\hline & \multicolumn{2}{|c|}{2014} & \multicolumn{2}{|c|}{2015} & \multicolumn{2}{|c|}{2016} & \multicolumn{2}{|c|}{2017} & \multicolumn{2}{|c|}{2018} \\
\hline & Frequency & $\%$ & Frequency & $\%$ & Frequency & $\%$ & Frequency & $\%$ & Frequency & $\%$ \\
\hline Exotropia & 238 & 59.20 & 192 & 58.18 & 291 & 51.78 & 270 & 63.38 & 255 & 57.17 \\
\hline Esotropia & 133 & 33.08 & 103 & 31.21 & 207 & 36.83 & 116 & 27.23 & 138 & 30.94 \\
\hline Paralytic & 19 & 4.73 & 28 & 8.48 & 29 & 5.16 & 16 & 3.76 & 30 & 6.73 \\
\hline Intermittent & 12 & 2.99 & 7 & 2.12 & 35 & 6.23 & 24 & 5.63 & 23 & 5.16 \\
\hline
\end{tabular}

*2018 data upto September only.

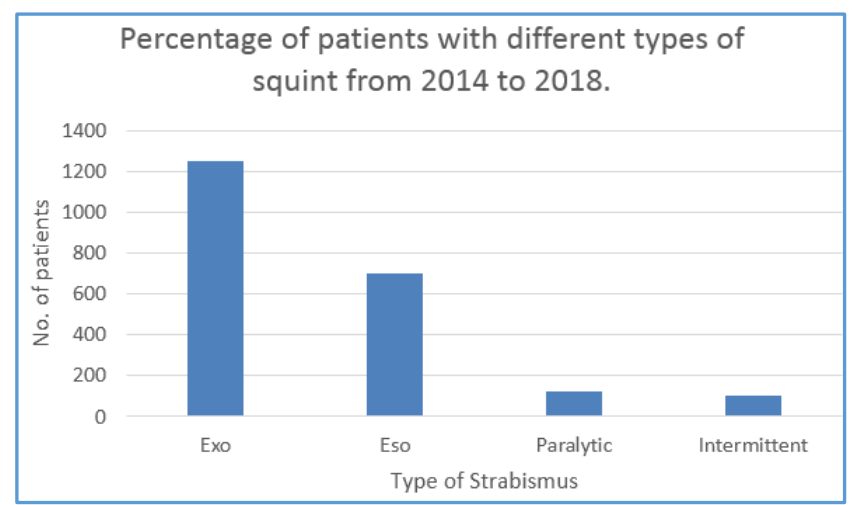

Figure 3. Demonstration of Overall Percentage of Patients with Different Types of Strabismus from 2014 to 2018

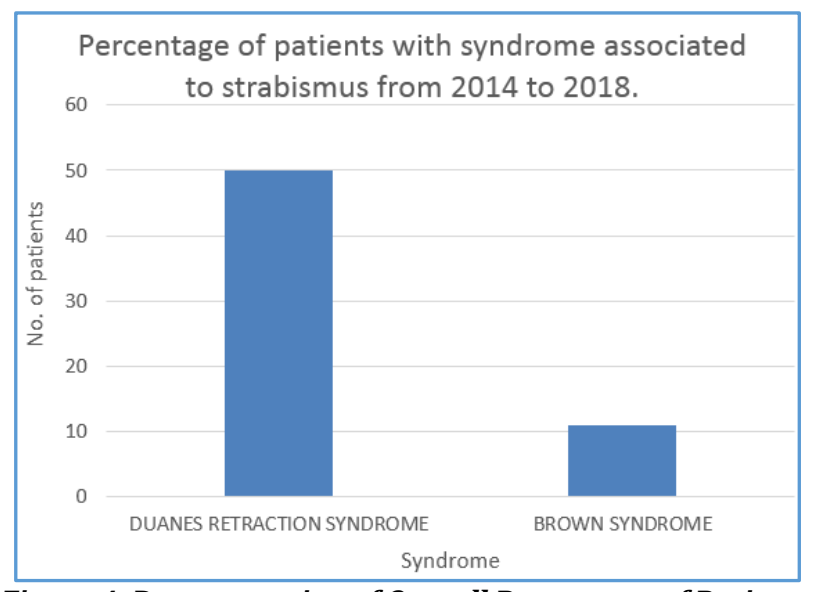

Figure 4. Demonstration of Overall Percentage of Patients with Syndrome associated to Strabismus from 2014 to 2018

*2018 data upto September only

\begin{tabular}{|c|c|c|c|c|c|c|c|c|c|c|}
\hline \multirow{3}{*}{$\begin{array}{l}\text { Prevalence of Syndrome } \\
\text { Associated Strabismus }\end{array}$} & \multicolumn{10}{|c|}{ Year } \\
\hline & \multicolumn{2}{|l|}{2014} & \multicolumn{2}{|c|}{2015} & \multicolumn{2}{|c|}{2016} & \multirow{2}{*}{\begin{tabular}{|c|}
2017 \\
Frequency \\
\end{tabular}} & \multirow[b]{2}{*}{$\%$} & \multirow{2}{*}{\begin{tabular}{|c|}
2018 \\
Frequency \\
\end{tabular}} & \multirow[b]{2}{*}{$\%$} \\
\hline & Frequency & $\%$ & Frequency & $\%$ & Frequency & $\%$ & & & & \\
\hline Duane Retract & 10 & 90.91 & 11 & 73.33 & 17 & 89.47 & 4 & 80.00 & 8 & 72.73 \\
\hline Brown Syndrome & 1 & 9.09 & 4 & 26.67 & 2 & 10.53 & 1 & 20.00 & 3 & 27.27 \\
\hline
\end{tabular}

*2018 data upto September only.

\section{DISCUSSION}

In our study, exotropia was more common than esotropia. This finding was similar to others where exotropia cases were greater than esotropia.7,8 In a study done among 322 cases of strabismus, 262 cases (81.4\%)were exotropia and 60 cases $(18.6 \%)$ were esotropia. ${ }^{9}$ In Cameroon, exotropia was found in $75 \%$ cases and esotropia in $25 \%$ of cases. ${ }^{10}$ Matsuo found that the prevalence of strabismus was $1.28 \%$ in which exotropia was the most prevalent than any other type of strabismus. ${ }^{11}$ In addition, in a population at Iran, exotropia accounted $1.3 \%$ whereas esotropia accounted $0.59 \%$ only. 12 Ahbdul Kabir et al. concluded in their study that $1.49 \%$ of the students had exotropia and none had esotropia. ${ }^{13}$ Similarly, Carlos Alexandre de Amorium Garcia et al. in a survey at Natal showed $2 \%$ exotropia, $0.6 \%$ esotropia and $0.2 \%$ intermittent exotropia. ${ }^{14}$

According to the present study, paralytic and intermittent type of strabismus was less frequently seen, and they constituted $5.63 \%$ and $4.6 \%$ cases, so they are not common 
types. In a hospital-based study in North India, 2\% had intermittent exotropia and $0.8 \%$ had paralytic strabismus. ${ }^{15}$

In our study, brown syndrome was present in $81.9 \%$ cases and Duane refraction syndrome was present in $18.03 \%$ cases from the year 2014 to 2018. Similar finding was reported by Abuimara in Gaza in 226 patients where these two groups together showed $14.1 \%$ of all cases. ${ }^{16}$ In a study done among 1309 patients with strabismus, only 5 cases (0.4\%) had Brown syndrome and 23 cases $(1.8 \%)$ had Duane refraction syndrome. ${ }^{17}$

The studies carried out in East Asian population, exotropia was the most common type of strabismus. The vast majority of strabismus cases in our study were of the exotropia type similar only to few studies and contradicting the equal part of the literature where esotropia exceeds over exotropia. $18-21$

\section{CONCLUSION}

Exotropia was found to be the most common type of strabismus in this population followed by esotropia, paralytic strabismus and intermittent exotropia being the least common. These data support the assumption that screening strabismus in developing countries could be useful in early detection, appropriate management and prevention of strabismus.

Early detection of strabismus and proper treatment serves as a boon in reducing the social burden of a nation. More researches should be carried out to validate the role of consanguinity in strabismus. Extensive health education programs among children and their parents are needed to alleviate superstitious beliefs.

\section{REFERENCES}

[1] Sinhota R, Tandon R. Parsons' diseases of the eye. 20 th edn. Elsevier 2011.

[2] Attada TR, Deepika M, Laxmi S. Strabismus in paediatric age (3-16 year): a clinical study. International Journal of Research in Medical Sciences 2016;4(6):1903-9.

[3] Preslan MW, Novak A. Baltimore vision screening project. Ophthalmology 1996;103(1):105-9.

[4] Kothari M, Balanke S, Gawade R, et al. Comparison of psychosocial and emotional consequences of childhood strabismus on the families from rural and urban India. Indian J Ophthalmol 2009;57(4):285-8.

[5] Fawcett SL. Disruption and reacquisition of binocular vision in childhood and in adulthood. Curr Opin Ophthalmol 2005;16(5):298-302.

[6] Alshammari M, Alhibshi N, Almusallam A, et al. Risk factors for developing different subtypes of strabismus in a Saudi population. International Journal of Medical and Health Research 2017;3(11):116-20.
[7] Arnold RW. Amblyopia and strabismus prevalence. Ophthalmology 2009;116(2):365-6.

[8] Tinley C, Grotte R. Comitant horizontal strabismus in South African black and mixed race children-a clinic based study. Ophthalmic Epidemiology 2012;19(2):89-94.

[9] Rah SH, Jun HS, Kim SH. An epidemiologic survey of strabismus among school children in Korea. Journal of Korean Opthalmol Society 1997;38(12): 2195-9.

[10] Mvogo CE, Ellong A, Bella-Hiag AL, et al. Hereditary factors in strabismus. Sante 2001;11(4):237-9.

[11] Matsuo T, Matsuo C. The prevalence of amblyopia and strabismus and amblyopia among Japanese elementary school children. Ophthalmic Epidemiology 2005;12(1):31-6.

[12] Yekta A, Fotouhi A, Hashemi H, et al. The prevalence of anisometropia, amblyopia and strabismus in school children of Shiraz, Iran. Strabismus 2010;18(3):10410.

[13] Abdul-Kabir M, Abdul-Sadik A, Ansah DO, et al. Prevalence of anisometropia, strabismus and amblyopia among first year opthometry students in Kwame Nkrumah University of Science and Technology, Ghana. M J Opht 2017;2(2):18.

[14] De Amorium GCA, De Sousa AB, De Melo MMB, et al. Prevalence of strabismus among students in Natal/RN - Brazil. Arq Bras Oftalmol 2004;67(5):791-4.

[15] Akhtar N, Gupta S. Prevalence of types of strabismus in pediatric patients in a tertiary centre of North India. IOSR Journal of Dental and Medical Sciences 2017;16(6):61-4.

[16] Amer A. Relative prevalence of various types of strabismus in patients attending NGO's medical centers in Gaza Strip. Science Journal of Public Health 2015;3(1):1-5.

[17] Torp-Pedersen T, Boyd HA, Skotte L, et al. Strabismus incidence in Danish population-based cohort of children. JAMA Ophthalmol 2017;135(10):1047-53.

[18] Ohlsson J, Villarreal G, Sjostrom A, et al. Visual acuity, residual amblyopia and ocular pathology in a screened population of 12-13-year-old children in Sweden. Acta Ophthalmol Scand 2001;79(6):589-95.

[19] Preslan MW, Novak A. Baltimore vision screening project. Phase 2. Ophthalmology 1998;105(1):150-3.

[20] Schimiti RB, Costa VP, Gregui MJF, et al. Prevalence of refractive errors and ocular disorders in preschool and school children of Ibiporã-PR, Brazil (1989 to 1996). Arq Bras de Oftalmol 2001;64(5):379-84.

[21] Kvarnstrom G, Jakobsson P, Lennerstrand G. Visual screening of Swedish children: an ophthalmological evaluation. Acta Ophthalmol Scand 2001;79(3):240-4. 